Altman DG, eds. Statistics in practice. London: British Medical Association, 1982:44-7

12 Wade DT, Wood VA, Heller A, Maggs J, Langton Hewer R. Walking after stroke. Scand f Rehab Med 1987;19:25-30.

13 Ashburn A. A physical assessment for stroke patients. Physiotherapy 1982;68: 109-13.

14 Wade DT, Legh-Smith J, Langton Hewer R. Social activities after stroke: measurement and natural history using the Frenchay activities index. Int Rehabil Med 1985; 7:176-81.

15 Hunt SM, McEwen J, Mckenna SP. Measuring health status. London: Croom Helm, 1986

16 Ebrahim S, Barer D, Nouri F. Use of the Nottingham health profile with patients after a stroke. $\mathcal{F}$ Epidemiol Conmunity Health 1986;40:166-9.

17 Goldberg DP, Hillier VF. A scaled version of the general health questionnaire. Psychol Med 1979;9:139-45.

18 Altman DG. How large a sample? In: Gore SM, Altman DG, eds. Statistics in practice. London: British Medical Association, 1982:6-8.

19 Campbell MJ, Gardner MJ. Calculating confidence intervals for some nonparametric analyses. In: Gardner MJ, Altman DG, eds. Statistics with confidence. London: $B M \mathcal{A}, 1989: 71-9$.

20 Wade DT, Langton Hewer R, Skilbeck CE, Bainton D, Burns-Cox C.
Controlled trial of a home-care service for acute stroke patients. Lance $1985 ; \mathrm{i}: 323-6$

21 Goldberg DP, Williams P. A users's guide to the general health questionnaire. Windsor: Nfer-Nelson, 1988

22 Garraway WM, Akhtar AJ, Hockey L, Prescott RJ. Management of acut stroke in the elderly: follow up of a controlled trial. $B M \mathcal{F}$ 1980;281:827-9.

23 Burnard S. Development of a community physiotherapy service. Physiotherapy 1988;74:4-8.

24 Glossop ES, Smith DS. Domiciliary physiotherapy research project 1976 1978. Physiotherapy 1981;67:79.

25 Stokoe D, Zuccollo G. Travel sickness in patients attending a geriatric day hospital. Age Ageing 1985;14:308-11.

26 Hildick-Smith M. Geriatric rehabilitation in day hospitals. Int Rehabil Med 1985;7:120-4.

27 Ahlsio B, Britton M, Murray V, Theorell T. Disablement and quality of life after stroke. Stroke 1984;15:886-90.

28 Schmidt SM, Herman LM, Keonig P, Leuze M, Monahan MK, Stubber RW. Status of stroke patients: a community assessment. Arch Phys Med Rehabil 1986;67:99-102.
Department of Child and Adolescent Psychiatry, Guy's Hospital, London SE1 9RT

M R Wiseman, consultant child psychiatrist

\section{Tavistock Clinic, London NW3 \\ E Vizard, consultant \\ psychiatrist}

Hospital for Sick Children, Great Ormond Street, London WC1

A Bentovim, consultant psychiatrist

\section{Department of Pediatrics,} Yale University, New Haven, Connecticut, USA J Leventhal, consultant paediatrician

Correspondence to: $\mathrm{Dr}$ Wiseman.

BMf 1992;304: 1089-91

\title{
Reliability of video taped interviews with children suspected of being sexually abused
}

\author{
M R Wiseman, E Vizard, A Bentovim, J Leventhal
}

Abstract

Objective-To determine the reliability of judgments about the likelihood of child sexual abuse based only on video recorded interviews.

Design-Blinded rating of likelihood of abuse by seven professional groups and comparison with consensus rating.

Setting - Child and adolescent psychiatry centre. Subjects-Four people from each of seven professional disciplines: specialist psychiatrists, general psychiatrists, experimental psychologists, trainee social workers, trainee clinical psychologists, lawyers, and police.

Main outcome measure-Rating of 12 recorded interviews.

Results-Agreement between the consensus panel and professional groups was $83 \%(151 / 183)$ for high likelihood cases (seven cases) and $89 \%(118 / 132)$ for low likelihood cases (five). Specialist psychiatrists and the police were better able to identify high likelihood cases than were other groups with less experience of interviewing sexually abused children (91\% (48/53) v 79\% (102/129); $\mathrm{p}=0.05)$.

Conclusions - Raters could accurately distinguish children with low likelihood of abuse on interview evidence alone, but those with more experience of dealing with sexual abuse were better at identifying high likelihood cases.

\section{Introduction}

In the mid-1980s the courts and the Butler-Sloss inquiry ${ }^{1}$ criticised methods used for interviewing children suspected of being sexually abused. These criticisms suggested that such interviews were conducted poorly and used hypothetical and leading questions and that the information elicited from children and a subsequent interpretation of this videorecorded material by clinicians were unreliable as evidence.

Anatomical dolls and other play adjuncts were used in the recorded interviews, and the play, non-verbal, and verbal responses of the child were subsequently scrutinised for evidential meaning by lawyers in court. Research into children's memory and suggestibility indicates that very young children can recall events of central importance as accurately as older children but that younger children can give less detailed accounts of such events and are more easily pressured into compliant responses by suggestible or leading interview techniques. ${ }^{2}$ Studies comparing the effects of anatomically correct dolls on the play of abused and nonabused children show that sexually abused children may show both sexualised and agressive play with the dolls whereas non-abused children's play is unremarkable. ${ }^{3}$ There is no convincing evidence to suggest any sexualising effect of such dolls on young children's play, and sometime after the Cleveland report ${ }^{1}$ Westcott et al stated that "there seems no good reason to immediately remove the dolls from use in diagnostic therapeutic interviews with suspected child abuse victims."

We used anatomical dolls in video recorded interviews with children suspected of being sexually abused. The interviews were then assessed by blinded raters from five disciplines, including lawyers, to test the reliability of their professional perceptions. The experimental design in some ways reflected the artificiality of the court situation in the mid-1980s, when there was often an over emphasis on the video recorded interview and the use of antomical dolls.

\section{Subjects and methods}

Twelve children aged between 3 and 9 years were included in the study. They had all been referred to child psychiatry teams specialising in the management and treatment of child sexual abuse to investigate the possibility of sexual abuse.

All the children were interviewed by clinicians experienced in dealing with sexual abuse by using a semistructured interview. ${ }^{5}$ The interviews were primarily clinical, responding to the needs of the children, and as such were not pure research interviews. Although the interviews were not chosen at random, the children were representative of those referred to the teams and the interviews were typical of those conducted by the teams. The interviews were chosen on the basis of the age of the child, the technical quality of the video recording of the interview, and the degree to which the interview conformed to the semistructured format. In addition we ensured that the interviews included children who were thought to have a high likelihood as well as a low likelihood of having been abused.

We rated the non-interview data on the children derived from information obtained at the time of the referral, including physical findings, emotional and 
behavioural factors in the child, statements made by the child or adults, and family background. In addition, MRW and EV rated the interview data by viewing the videos independently. However, one researcher (EV) had carried out the interview in five out of the 12 cases and the other (MRW) had carried out the interview in one case so these ratings were not blind to all other information about the case. After discussion of the non-interview and the interview data we assessed the likelihood of sexual abuse as either high (definite or probable) or low (possible or unlikely). We formed the consensus group and our judgment about the likelihood of abuse constituted the consensus judgment in each case.

We asked four people from seven professiona disciplines to view independently the video of each of the 12 interviews. The reviewers were provided with no information about the child apart from the child's age. The seven groups were child psychiatrists specialising in child sexual abuse; experienced general child psychiatrists; experimental psychologists; trainee clinical psychologists; trainee social workers; lawyers; and police. The specialist child psychiatrists were not associated with, or trained in, the Great Ormond Street technique, ${ }^{5}$ and the general child psychiatrists had no special interest in child sexual abuse.

The experimental psychologists were included because of their expertise in observing behavioural data, although we recognised that they were not clinically experienced. The trainee groups were included to assess the effect of having inexperienced clinicians. A group of experienced social workers was also approached, but, unfortunately, for practical reasons they were unable to take part in the study. Lawyers were included as they are often asked to assess the likelihood of sexual abuse on the basis of interviews and other evidence. Similarly, the police were included as they too assess interviews of children suspected of having been sexually abused, as well as interviewing victims of abuse, for evidential purposes.

At the end of each interview the raters were asked to indicate their assessment of the likelihood of child sexual abuse as high (definite or probable), low (possible or unlikely), or unable to rate. They also were asked to explain why they had made their decisions. The results of the ratings of the likelihood of sexual abuse, based on the interview alone, were compared with the consensus panel's rating.

\section{Results}

Table I shows the agreement between the raters and the consensus group, based on the interview alone. For the cases rated as showing a high likelihood of abuse by the consensus group there was $83 \%$ agreement in the ratings of the experimental group. For the cases rated as low likelihood by the consensus group there was $89 \%$ agreement of the ratings. The differences between the consensus and experimental ratings were not significant.

TABLE I-Agreement of professional groups with ratings of consensus panel about likelihood of sexual abuse

\begin{tabular}{|c|c|c|c|c|c|c|}
\hline & \multicolumn{3}{|c|}{ Consensus rating high likelihood ( 7 cases) } & \multicolumn{3}{|c|}{ Consensus rating low likelihood ( 5 cases) } \\
\hline & $\begin{array}{c}\text { High } \\
\text { likelihood }\end{array}$ & $\begin{array}{c}\text { Low } \\
\text { likelihood }\end{array}$ & $t$ Value & $\begin{array}{c}\text { High } \\
\text { likelihood }\end{array}$ & $\begin{array}{c}\text { Low } \\
\text { likelihood }\end{array}$ & $t$ Value \\
\hline Specialist psychiatrists & 23 & 3 & 0.93 & 2 & 18 & 0.74 \\
\hline General psychiatrists & 14 & 7 & $1 \cdot 76$ & 2 & 16 & 0.78 \\
\hline \multicolumn{7}{|l|}{ Experimental } \\
\hline psychologists & 21 & 6 & $1 \cdot 37$ & 1 & 19 & 0.52 \\
\hline Trainee social workers & 26 & 2 & 0.72 & 5 & 14 & 1.29 \\
\hline \multicolumn{7}{|l|}{ Trainee clinical } \\
\hline psychologists & 21 & 6 & 1.76 & 2 & 18 & 0.74 \\
\hline Lawyers & 20 & 6 & $1 \cdot 41$ & & 16 & \\
\hline Police & 26 & 2 & 0.72 & 2 & 17 & 0.75 \\
\hline All groups & 151 & 32 & 1.22 & $\ldots 14$ & 118 & 0.74 \\
\hline
\end{tabular}

For the cases rated as having high likelihood of abuse the specialist psychiatrists, police, and trainee social workers showed the most agreement with the consensus group (table I). However, the differences between the seven groups did not reach significance. Apart from the trainee social workers, there was good agreement both between the groups and with the consensus rating for low likelihood cases. There was no significant difference between the groups or between the groups and the consensus rating. The results suggest that it may be easier to reach agreement on cases in which there is a lower likelihood of abuse than when there is a higher likelihood.

We hypothesised that professionals with specific experience of face to face interviewing with abused children (the police and specialist psychiatrists) would be more consistently accurate in their assessments of the interviews. Table I suggests that this hypothesis is correct for high likelihood cases, although the difference between specialist groups and other groups was not significant. Trainee social workers were able to identify the higher likelihood cases more consistently than the other non-experienced groups but they were also more likely to rate the lower likelihood cases as high likelihood.

We therefore combined the police and specialist psychiatrists into one group and compared their ratings with those of the other five groups, also combined into one group (table II). For the high risk cases $91 \%$ of the specialist group ratings agreed with the consensus group compared with $79 \%$ of the other groups (48/53 $v 102 / 129 ; t=1 \cdot 85, \mathrm{p}=0.05)$, suggesting that the specialist group was better at identifying those children with a higher likelihood of abuse than were less experienced raters. For those cases judged to have a low likelihood of abuse $91 \%$ of the ratings of the specialist group agreed with the consensus group, compared with $89 \%$ of the non-specialist groups ratings $(35 / 39 v 83 / 93 ; t=0.85, \mathrm{NS})$; both groups were equally accurate in identifying cases with a low likelihood of abuse.

\section{Discussion}

This study had some methodological problems. Firstly, the 12 cases were not randomly selected and so may represent a biased sample, although knowledge of the case,material suggests that they were representative of typical cases seen by the teams. Nevertheless, it is difficult to extrapolate with great confidence from this study. Secondly, the professional groups contained only four people and were a selected sample, representing highly experienced, leading members of each professional group. Thirdly, it was not possible to get a full spread of all the appropriate professionals-for example, we had a group of trainee social workers, but not of qualified, experienced social workers. Lastly, there are also difficulties about the nature of a consensus rating. In clinical practice, there are no simple means of accurately concluding that sexual abuse has definitely occurred. The consensus rating was formed by raters independently assessing each case and reaching a decision after discussion.

With these reservations our study suggests that agreement between professional groups and the consensus panel was good when raters were asked to assess the likelihood of child sexual abuse on the basis of a video recorded interview. The agreement seems to be better for those cases with a lower likelihood of sexual abuse. Cases with a higher likelihood of sexual abuse were found more difficult to identify by raters, except those professionals-police and specialist child psychiatrists - who had more experience in interviewing children suspected of having been sexually abused.

Our study shows that video recorded interviews can 
TABLE II-Ratings of specialist group (specialist psychiatrists and police) compared with those of nonspecialists

\begin{tabular}{|c|c|c|c|c|}
\hline & \multicolumn{2}{|c|}{ Consensus rating high likelihood ( 7 cases) } & \multicolumn{2}{|c|}{ Consensus rating low likelihood ( 5 cases) } \\
\hline & High likelihood & Low likelihood & High likelihood & Low likelihood \\
\hline Specialist group & 48 & 5 & 4 & 35 \\
\hline Other groups & 102 & 27 & 10 & 83 \\
\hline
\end{tabular}

(one sided $\mathrm{p}$ Value)

be reliably assessed and that agreement can be achieved among professionals. Whereas most professionals can spot low likelihood cases on video, specific experience in conducting these interviews gives greater accuracy in picking out higher likelihood cases.

In this experimental situation, child sexual abuse was assessed on the artificial basis of only the interview with the child. However, considerable emphasis is already placed on the interview with the child, and this will increase with the introduction of video recorded assessments in criminal as well as civil cases. Such interviews should be carried out by experienced professionals who are trained to perform the interviews. ${ }^{6}$
This research indicates that it may also be necessary for such professionals to assess video recorded interviews carried out by others in order to help courts to determine the likelihood of abuse having occurred.

We thank our raters, Jane Hughes, colleagues in the academic department of the Institute of Child Health, and in particular Marjorie Smith and Elizabeth Monck.

1 Butler-Sloss E. Report of the inquiry into child abuse in Cleveland 1987. London: HMSO, 1988.

2 Davies G. Research on children's testimony-implications for interviewing practice. In: Hollin C, Howells $\mathrm{K}$, eds. Clinical approaches to sex offenders and their victims. New York: Wiley, 1991.

3 Vizard E. Interviewing children: a review of theory and practice. In: Hollin CR, Howells $\mathrm{K}$, eds. Clinical approaches to sex offenders and their victims. New York: Wiley, 1991.

4 Westcott H, Davies G, Clifford B. The use of anatomical dolls in child witness interviews. Adoption and Fostering 1989;13:6-14.

5 Vizard $E$, Tranter $M$. Helping children describe experiences of child sexual abuse - a guide to practice. In: Bentovim A, Elton A, Hildebrand J, Tranter $M$, Vizard $\mathrm{E}$, eds. Child sexual abuse within the family. Assessment and M, Vizard E, eds. Child sexual abuse within the family. Assessment and
treatment. Guildford: Wright, 1988:105-29.

6 Working together under the Children Act 1989. A guide to arrangements for interagency co-operation for the protection of children from abuse. London: interagency co-

(Accepted 18 February 1992)

\section{Leiden University}

Hospital, 2300 RC Leiden, Netherlands

Anne M Lagaay, research fellow, gerontology section, department of pathology

Jan C van der Meij, medical student

Willy Hijmans, professor of medicine, gerontology section, department of pathology

Correspondence to:

Department of Internal

Medicine, Leiden

University Hospital, Building 1, C1 R-41, PO Box 9600,2300 RC Leiden, Netherlands.

BMF 1992;304:1091-2
Dr A M Lagaay,

\section{Validation of medical history taking as part of a population based survey in subjects aged 85 and over}

\section{Anne M Lagaay, Jan C van der Meij, Willy Hijmans}

In geriatric medical practice and in epidemiological surveys doctors rely heavily on the information obtained from the medical history. In elderly subjects the accuracy of this information is questionable because of the possible existence of sensory or cognitive impairment. Also, elderly subjects may not be familiar with multiple choice forms, questionnaires, and informed consent papers.

Two studies of the usefulness of history taking in elderly subjects found no evidence that the accuracy of factual information obtained from older adults, even those with moderate cognitive impairment, was less than in younger age groups. ${ }^{23}$

The accuracy or validity of the information obtained

Observed differences between information obtained by medical history taking and from medical records of general practitioners for 60 subjects aged 85 or over. Figures are number (percentage) of diagnoses

\begin{tabular}{|c|c|c|c|c|}
\hline Diagnoses & Total & $\begin{array}{l}\text { Reported by } \\
\text { general practitioner } \\
\text { and in study }\end{array}$ & $\begin{array}{c}\text { Reported by } \\
\text { general practitioner } \\
\text { alone }\end{array}$ & $\begin{array}{l}\text { Reported in } \\
\text { study alone }\end{array}$ \\
\hline Surgery & 89 & $64(72)$ & $17(19)$ & $8(9)$ \\
\hline Infections & 19 & $4(21)$ & $11(58)^{\star}$ & $4(21)$ \\
\hline Tuberculosis & 5 & $4(80)$ & & $1(20)$ \\
\hline Pneumonia & 8 & $7(88)$ & $1(12)$ & \\
\hline Chronic obstructive airways disease & 14 & $10(71)$ & $3(21)$ & $1(7)$ \\
\hline Malignancies & 12 & $8(67)$ & $4(33)^{\star}$ & \\
\hline Cerebrovascular accident & 9 & $7(78)$ & $1(11)$ & $1(11)$ \\
\hline Angina pectoris & 13 & $9(69)$ & $3(23)$ & $1(8)$ \\
\hline Myocardial infarction & 9 & $7(78)$ & $1(11)$ & $1(11)$ \\
\hline Claudication & 6 & 2 & 2 & \\
\hline Hypertension & 21 & $17(81)$ & $3(14)$ & $1(5)$ \\
\hline Heart failure & 11 & $7(64)$ & $4(36)^{\star}$ & \\
\hline Osteoporosis & 6 & $4(67)$ & $2(33)$ & \\
\hline Fractures & 11 & $6(55)$ & $5(45)^{\star}$ & \\
\hline Arthrosis & 12 & 6 & $4(33)$ & $2(17)$ \\
\hline Non-insulin dependent diabetes & 13 & $7(54)$ & $3(23)$ & $3(23)$ \\
\hline Depression & 3 & 1 & 2 & \\
\hline Dementia & 13 & $9(69)$ & & $4(31)^{\star}$ \\
\hline Visual impairment & 30 & $11(37)$ & $1(3)$ & $18(60)^{\star}$ \\
\hline Hearing impairment & 25 & $10(40)$ & $1(4)$ & $14(56)^{\star}$ \\
\hline Urinary incontinence & 16 & $1(6)$ & $1(6)$ & $14(88)^{\star}$ \\
\hline
\end{tabular}

^For this disorder one category scores considerably better than the other on $\chi^{2}$ testing. by medical history taking in subjects aged 85 and over has not been investigated to date. With the expected growth of this particular age group in the next decades, a significant part of gerontological-epidemiological research is directed at this group.

This study arose from a need to assess the validity of information obtained by medical history taking as part of a study of the total cohort of Dutch residents aged 85 and over in Leiden.

\section{Subjects, methods, and results}

The total cohort of residents aged 85 and over on the entry date of 1 December 1986 comprised 1259 subjects. Of these, 977 were visited at home by an internist ( 222 had died before they could be visited and 60 refused). All had a medical history taken and the minimental state examination performed. ${ }^{4}$

The medical history from 60 participants chosen randomly from four general practices was compared with the medical record of the general practitioner. Their age and sex distributions and examination scores did not differ significantly from those of the total study population $(\mathbf{n}=977)$ by $\chi^{2}$ analysis. The distribution of the prevalences of the investigated disorders did not differ between the selected participants and the total study population. Three categories were distinguished for the most frequently occurring diagnoses and disorders: diagnoses and disorders reported both by the general practitioner and in this study, those reported by only the general practitioner, and those reported in only this study (table). For most diagnoses there was a good agreement. The general practitioners record was more complete for some infectious diseases, malignancies, and heart failure. Urinary incontinence, visual and hearing impairments, and dementia were more frequently detected in this study.

\section{Comment}

In almost a third of all cases of dementia the diagnosis was not registered by the general practitioner, confirming the results of O'Connor et al, who found that general practitioners correctly identified about $60 \%$ of all cases of dementia. ${ }^{5}$ The fact that many of the cases of sensory impairment, urinary incontinence, and dementia in patients were not known to their general practitioner should provide a strong incentive 